University of Wollongong

Research Online

Faculty of Engineering and Information

Faculty of Engineering and Information

Sciences - Papers: Part A

Sciences

$1-1-2013$

\title{
Enhanced rate performance of cobalt oxide/nitrogen doped graphene composite for lithium ion batteries
}

\author{
Dan Li \\ University of Wollongong, danli@uow.edu.au \\ Dongqi Shi \\ University of Wollongong, dongqi@uow.edu.au \\ Zhixin Chen \\ University of Wollongong, zchen@uow.edu.au \\ Hua-Kun Liu \\ University of Wollongong, hua@uow.edu.au \\ Dianzeng Jia \\ Key Laboratory of Advanced Functional Materials of Autonomous Region
}

See next page for additional authors

Follow this and additional works at: https://ro.uow.edu.au/eispapers

Part of the Engineering Commons, and the Science and Technology Studies Commons

Research Online is the open access institutional repository for the University of Wollongong. For further information contact the UOW Library: research-pubs@uow.edu.au 


\title{
Enhanced rate performance of cobalt oxide/nitrogen doped graphene composite for lithium ion batteries
}

\begin{abstract}
Ultrafine Co304 nanocrystals homogeneously attached to nitrogen doped reduced graphene oxide (rGO) by the hydrothermal reaction method are demonstrated as anode materials for lithium ion batteries. Transmission electron microscope images revealed that the crystal size of Co3O4 in Co304/N-rGO and Co304/rGO is $5-10 \mathrm{~nm}$, much smaller than that of bare C0304, indicating that the reduced graphene oxide sheets with $\mathrm{Co} 3 \mathrm{O} 4$ nanocrystals attached could hinder the growth and aggregation of $\mathrm{Co} 3 \mathrm{O} 4$ crystals during synthesis. The graphene sheets can also effectively buffer the volume change of Co304 upon lithium insertion/extraction, thus improving the cycling performance of the composite electrodes. The doped nitrogen on the reduced graphene oxide can not only improve the conductivity of the graphene sheets, but also introduce defects to store lithium and enhance the connection of the 00304 nanocrystals to the graphene sheet, leading to better distribution of $\mathrm{Co} 304$ on the graphene sheets, and enhanced rate performance. The nitrogen doping combined with the unique structural features is a promising strategy for the development of electrode materials for lithium ion batteries with high electrochemical performance.
\end{abstract}

\section{Keywords}

graphene, doped, nitrogen, oxide, cobalt, composite, performance, lithium, rate, enhanced, ion, batteries

\section{Disciplines}

Engineering | Science and Technology Studies

\section{Publication Details}

Li, D., Shi, D., Chen, Z., Liu, H. K., Jia, D. \& Guo, Z. (2013). Enhanced rate performance of cobalt oxide/ nitrogen doped graphene composite for lithium ion batteries. Rsc Advances, 3 (15), 5003-5008.

\section{Authors}

Dan Li, Dongqi Shi, Zhixin Chen, Hua-Kun Liu, Dianzeng Jia, and Zaiping Guo 


\title{
Journal of Materials Chemistry
}

PAPER

\section{Enhanced Rate Performance of Cobalt Oxide/Nitrogen Doped Graphene Composite for Lithium Ion Batteries}

\author{
Dan Li, ${ }^{a}$ Dongqi Shi ${ }^{a}$, Zhixin Chen ${ }^{b}$, Huakun Liu ${ }^{a}$, Dianzeng $\mathrm{Jia}^{\mathrm{c}}$ and Zaiping Guo ${ }^{* a b}$
}

Ultrafine $\mathrm{Co}_{3} \mathrm{O}_{4}$ nanocrystals homogeneously attached to nitrogen doped reduced graphene oxide (rGO) by the hydrothermal reaction method are demonstrated as anode materials for the lithium ion battery. Transmission electron microscope images revealed that the crystal size of $\mathrm{Co}_{3} \mathrm{O}_{4}$ in $\mathrm{Co}_{3} \mathrm{O}_{4} / \mathrm{N}-\mathrm{rGO}$ and $\mathrm{Co}_{3} \mathrm{O}_{4} / \mathrm{rGO}$ is $5-10 \mathrm{~nm}$, much smaller than that of bare $\mathrm{Co}_{3} \mathrm{O}_{4}$, indicating that the reduced graphene oxide sheets with $\mathrm{Co}_{3} \mathrm{O}_{4}$ nanocrystals attached could hinder the growth and aggregation of $\mathrm{Co}_{3} \mathrm{O}_{4}$ crystals during synthesis. The graphene sheets can also effectively buffer the volume change of $\mathrm{Co}_{3} \mathrm{O}_{4}$ upon lithium insertion/extraction, thus improving the cycling performance of the composite electrodes. The doped nitrogen on the reduced graphene oxide can not only improve the conductivity of the graphene sheets, but also introduce defects to store lithium and enhance the connection of the $\mathrm{Co}_{3} \mathrm{O}_{4}$ nanocrystals to the graphene sheet, leading to better distribution of $\mathrm{Co}_{3} \mathrm{O}_{4}$ on the graphene sheets, and enhanced rate performance. The nitrogen doping combined with the unique structural features is a promising strategy for the development of electrode materials for lithium ion batteries with high electrochemical performance.

\section{Introduction}

Due to the gradual depletion of conventional energy sources, lithium ion battery technology is attracting widespread attention with a view to its wide application in portable electronic devices and hybrid electric vehicles. ${ }^{1-4}$ Increasing efforts have been focused on fabricating electrode materials to meet the demand for batteries with high energy density, high power density, and long cycling life. Among the candidate electrode materials under intensive investigation, $\mathrm{Co}_{3} \mathrm{O}_{4}$ has received particular interest due to its promising potential and high theoretical capacity $(890 \mathrm{~mA} \mathrm{~h}$ $\mathrm{g}^{-1}$ ), which is two times larger than that of graphite (327 $\mathrm{mA} \mathrm{h} \mathrm{g}^{-}$ ${ }^{1}$ ). However, its large irreversible capacity loss and poor cycling stability have restricted its general application, owing to the large volume change during the charge/discharge process and, the unavoidable particle aggregation associated with the lithium ion insertion and extraction processes after long cycling. ${ }^{5-8}$ It is well accepted that electrode with the proper nanosize distribution could reduce the path length of lithium ion transport and improve electrolyte penetration because of the large contact area between electrode and electrolyte, which greatly contributes to the electrochemical performance during cycling. ${ }^{9-11}$ A strategy has been utilized to circumvent the volume change and aggregation problems by hybridizing with conducting matrices, such as amorphous carbon coatings ${ }^{11}$ or carbon nanotubes, ${ }^{12}$ which could interlink $\mathrm{Co}_{3} \mathrm{O}_{4}$ particles to improve their electrochemical performance. Recently, graphene has come into wide use as an effective matrix to improve the electrochemical performance of electrode materials by providing rapid access for electrons and allowing good transportation of lithium from the active material and electrolyte. ${ }^{13-16}$ In addition, graphene in the composite materials could effectively inhibit aggregation of particles and the large volume swings during the charge/discharge process, which will result in stable cycling performance. ${ }^{17,18}$ It was reported that heteroatoms doped into the graphene lattice could modify the physical and chemical properties of the host materials. ${ }^{19-21}$ Nitrogen doping could modified the electronic properties through the introduction of pyridinic nitrogen and pyrrolic nitrogen, owing to the hybridization between the lone pair electrons of nitrogen and the $\pi$ system of graphene, as well as the stronger electronegativity of nitrogen compared to carbon. ${ }^{22-28}$ Du et al. ${ }^{29}$ applied the four probe method to measure the conductivity and found that the conductivity of $\mathrm{Fe}_{2} \mathrm{O}_{3} / \mathrm{N}-\mathrm{G}$ is about twice as high as that of $\mathrm{Fe}_{2} \mathrm{O}_{3} / \mathrm{G}$. The improved conductivity can be attributed to the decreased semiconducting gap due to nitrogen doping and the appearance of a finite density of states at zero energy in graphene. $^{30}$

In this paper, we have synthesized cobalt oxide and reassembled it with nitrogen doped reduced graphene oxide (rGO) hybrid anode material for lithium ion batteries. Compared to the traditional method of nitrogen doping, our method of using $\mathrm{NH}_{3} \cdot \mathrm{H}_{2} \mathrm{O}$ is cheaper and, easier to control, and the potential risk is much lower. ${ }^{31}$ The obtained nanosized $\mathrm{Co}_{3} \mathrm{O}_{4}$ particles are directly and homogeneously grown on a conductive network of $\mathrm{N}$-doped rGO, which could offer dimensional confinement of the $\mathrm{Co}_{3} \mathrm{O}_{4}$ nanoparticles by the surrounding graphene network, limiting the volume expansion upon lithium insertion. Furthermore, the distribution of $\mathrm{Co}_{3} \mathrm{O}_{4}$ on the $\mathrm{N}$ doped graphene sheets is improved compared to that on the un-doped graphene.The nitrogen doping could be expected to improve the conductivity of the rGO sheets, and thus the composite material 
as a whole.

\section{Experimental}

Graphene oxide (GO) was synthesized from natural graphite powder by a modified Hummers method. ${ }^{32,33} 10 \mathrm{mg}$ of the obtained GO was dispersed in $45 \mathrm{~mL}$ of anhydrous ethanol by ultrasonication for $0.5 \mathrm{~h}$. $1 \mathrm{~mL}$ of $0.25 \mathrm{M}$ cobalt acetate solution and $1 \mathrm{~mL}$ of ammonia solution $\left(\mathrm{NH}_{4} \mathrm{OH}, 30 \mathrm{wt} \%\right)$ were added to the graphene oxide solution. The obtained composite precursor was stirred for several hours at $80{ }^{\circ} \mathrm{C}$ to ensure a complete hydrolysis reaction. Then, the solution was transferred into a Teflon-lined stainless steel reactor and heated at $150{ }^{\circ} \mathrm{C}$ for $3.5 \mathrm{~h}$. After the reaction, a black powder was collected by centrifugation and washed with de-ionized water and ethanol several times before drying it in an oven at $90{ }^{\circ} \mathrm{C}$ overnight. A similar approach has been reported by recently by Liang et al. using ammonia solution as dopant to synthesize $\mathrm{Co}_{3} \mathrm{O}_{4} / \mathrm{N}-\mathrm{rGO} .{ }^{31}$ Samples of rGO, $\mathrm{N}$-rGO, bare $\mathrm{Co}_{3} \mathrm{O}_{4}$, and $\mathrm{Co}_{3} \mathrm{O}_{4} / \mathrm{rGO}$ were also prepared for comparison. The experimental steps for these samples were the same as for the synthesis of $\mathrm{Co}_{3} \mathrm{O}_{4} / \mathrm{N}-\mathrm{rGO}$, but without the $\mathrm{NH}_{4} \mathrm{OH}$ and cobalt acetate solution for rGO, without cobalt acetate solution for N-rGO, without any GO for the bare $\mathrm{Co}_{3} \mathrm{O}_{4}$, and with the replacement of $\mathrm{NH}_{4} \mathrm{OH}$ by de-ionized water for $\mathrm{Co}_{3} \mathrm{O}_{4} / \mathrm{rGO}$.

The crystalline phases of the resulting materials were analyzed by powder X-ray diffraction (XRD, MMA GBC, Australia), which was carried out using $\mathrm{Cu} \mathrm{K} \alpha$ radiation $(\lambda=1.54056 \AA)$ from $2 \theta$. $=10$ to $80^{\circ}$. Thermogravimetric analysis (TGA) was carried out to determine the carbon content with a TGA/differential scanning calorimetry (DSC) type instrument (METTLER TOLEDO, Switzerland) at a heating rate of $10^{\circ} \mathrm{C}$ $\mathrm{min}^{-1}$ from room temperature to $800{ }^{\circ} \mathrm{C}$ in air. Transmission electron microscope (TEM) investigations were performed using a JEOL 2011F analytical electron microscope (JEOL, Tokyo, Japan) operating at $200 \mathrm{keV}$. X-ray photoelectron spectroscopy (XPS) experiments were carried out on a VG Scientific ESCALAB 220IXL instrument using aluminium $\mathrm{K} \alpha \mathrm{X}$-ray radiation during XPS analysis.

To prepare the working electrode for electrochemical testing, a slurry was prepared by thoroughly mixing 76 wt.\% active material, 12 wt.\% acetylene black, and 12 wt.\% poly(vinylidene fluoride) (PVdF) in $N$-methyl pyrrolidinone (NMP) solvent. The slurry was then spread onto copper foil substrates and dried in a vacuum oven at $120{ }^{\circ} \mathrm{C}$ for $3 \mathrm{~h}$. The electrochemical tests were carried out on CR2032 coin type cells. The cells were constructed of lithium foil as anode, the prepared active material on copper as cathode, microporous polyethylene (Celgard 2400) as the separator, and $1 \mathrm{M} \mathrm{LiPF}_{6}$ in a mixture of ethylene carbonate (EC) and dimethyl carbonate (DMC) (1:1 by volume) as the electrolyte. The whole assembly process was carried out in an argon-filled glove box (Mbraun, Unilab, Germany). The charge/discharge cycling was performed within the voltage range of 0.01-3 V vs $\mathrm{Li}^{+} / \mathrm{Li}$ on a battery test instrument (CT2001A, KINGNUO, China) at ambient temperature. Electrochemical impedance spectroscopy (EIS) were obtained by applying a dc potential equal to the open circuit voltage of the cell with an amplitude of $5 \mathrm{mV}$ over the frequency range from $100 \mathrm{kHz}$ to $0.01 \mathrm{~Hz}$.

\section{Results and discussion}

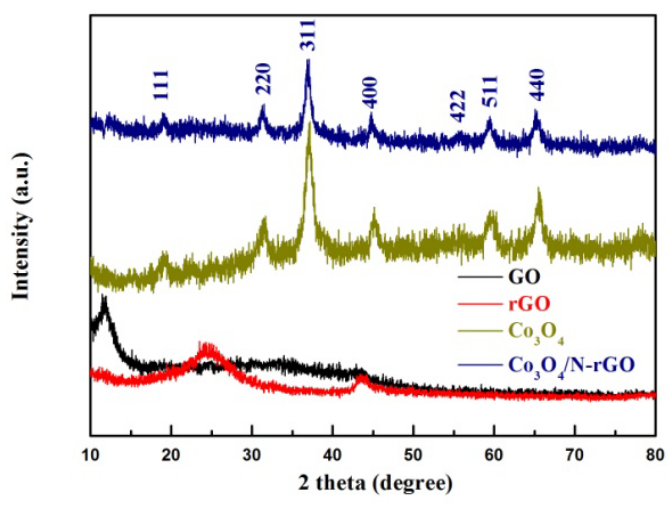

Fig. 1 Powder XRD patterns of GO, rGO, bare $\mathrm{Co}_{3} \mathrm{O}_{4}$, and $\mathrm{Co}_{3} \mathrm{O}_{4} / \mathrm{N}-\mathrm{rGO}$.

a

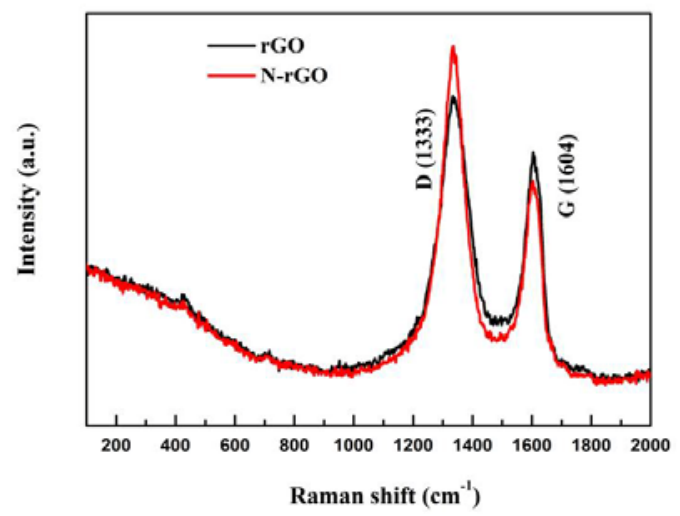

b

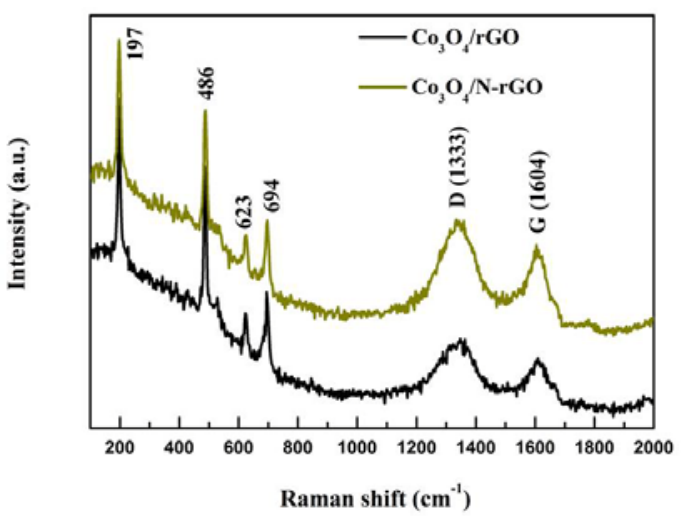

Fig. 2 Raman spectra of (a) rGO and N-rGO, (b) $\mathrm{Co}_{3} \mathrm{O}_{4} / \mathrm{rGO}$ and $\mathrm{Co}_{3} \mathrm{O}_{4} / \mathrm{N}-\mathrm{rGO}$ composite.

The obtained GO, rGO, bare $\mathrm{Co}_{3} \mathrm{O}_{4}$, and $\mathrm{Co}_{3} \mathrm{O}_{4} / \mathrm{N}$-rGO were investigated by powder $\mathrm{X}$-ray diffraction to confirm the phases. As illustrated in Fig. 1, the characteristic (002) peak shifted from $11.4^{\circ}$ for GO to $24.1^{\circ}$ for rGO, which indicates that the GO can be reduced during the in situ hydrothermal reaction. The interplanar spacing corresponding to the (002) peak of rGO $(0.376 \mathrm{~nm})$ is larger than that of standard graphite $(0.335 \mathrm{~nm}){ }^{34}$ giving evidence that oxygen-containing functional groups had 
been generated, providing additional intercalation sites for accommodation of lithium ions and therefore promoting enhanced electrochemical performance. ${ }^{14,15}$ The major diffraction peaks of the bare $\mathrm{Co}_{3} \mathrm{O}_{4}$ are well ascribed to the pure phase of crystallized cubic spinel $\mathrm{Co}_{3} \mathrm{O}_{4}$ with space group $\mathrm{Fd3m}(227)$ (JCPDS card No. 42-1467). For the $\mathrm{Co}_{3} \mathrm{O}_{4} / \mathrm{N}-\mathrm{rGO}$ sample, no distinct peak could be indexed to graphene as compared with the
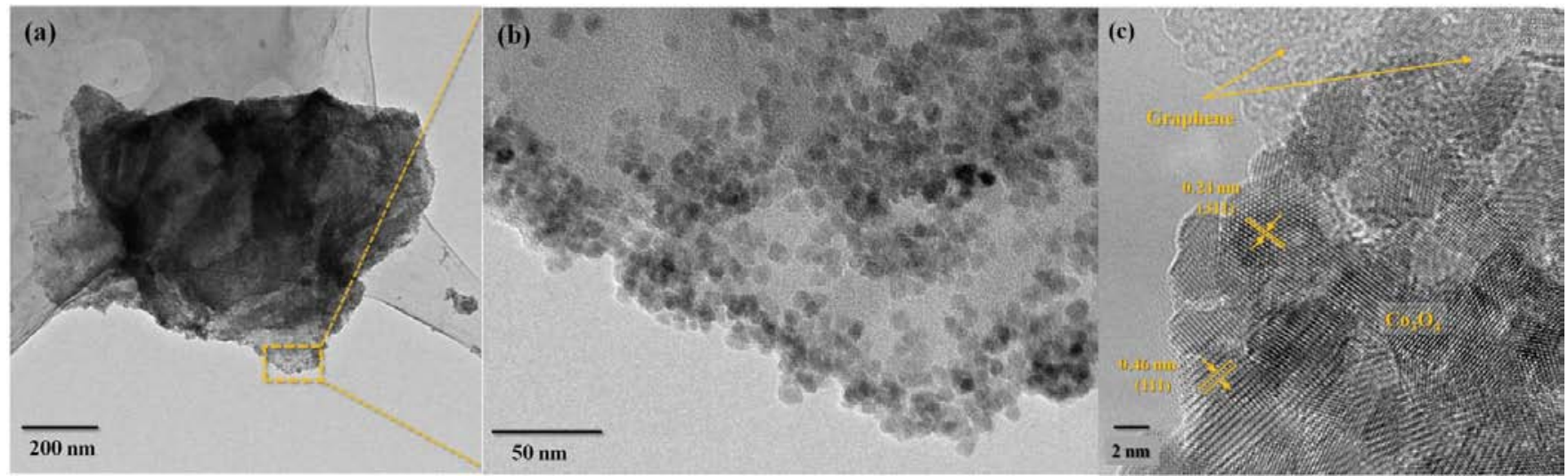

Fig. 3 (a) Low-magnification TEM, (b) high-magnification TEM, and (c) high-resolution TEM images of the obtained $\mathrm{Co}_{3} \mathrm{O}_{4} / \mathrm{N}^{-\mathrm{rGO}}$ composite.

bare $\mathrm{Co}_{3} \mathrm{O}_{4}$, which indicates that there was no critical aggregation problem for the graphene layers in the as-prepared composite and that the $\mathrm{Co}_{3} \mathrm{O}_{4}$ nanoparticles were homogeneously anchored on the surface of the rGO. The average particle size based on the main (311) peak for $\mathrm{Co}_{3} \mathrm{O}_{4} / \mathrm{N}-\mathrm{rGO}$ is about $6.7 \mathrm{~nm}$, calculated through Scherrer's equation, and this is well consistent with the results from high resolution TEM (HRTEM) analysis. Thermogravimetric analysis was carried out to evaluate the mass ratio of $\mathrm{Co}_{3} \mathrm{O}_{4}$ in the $\mathrm{Co}_{3} \mathrm{O}_{4} / \mathrm{N}-\mathrm{rGO}$ composite from $50{ }^{\circ} \mathrm{C}$ to 900 ${ }^{\circ} \mathrm{C}$ in air. The results revealed that the percentage of $\mathrm{Co}_{3} \mathrm{O}_{4}$ in the composite is about $76 \%$ (see Supplementary Information Fig. S1).

Raman spectroscopy is a useful tool for the characterization of graphene based materials, as shown in Fig. 2. ${ }^{35}$ From Fig. 2(a), it can be observed that there is a strong $D$ band at $1333 \mathrm{~cm}^{-1}$, which is related to the presence of defects, and a $\mathrm{G}$ band at $1604 \mathrm{~cm}^{-1}$, which is ascribed to the $E_{2 g}$ mode for $\mathrm{sp}^{2}$ domains in both samples. ${ }^{36}$ Note that the intensity ratio of the $\mathrm{D}$ band to the $\mathrm{G}$ band $\left(I_{\mathrm{D}} / I_{\mathrm{G}}\right)$ for the N-rGO is much higher than for the rGO, which indicates that there are more defects in the rGO after nitrogen doping. As shown in Fig. 2(b), the $I_{\mathrm{D}} / I_{\mathrm{G}}$ value of $\mathrm{Co}_{3} \mathrm{O}_{4} / \mathrm{N}$-rGO sample (1.2924) is higher than in the $\mathrm{Co}_{3} \mathrm{O}_{4} / \mathrm{rGO}$ sample (with a ratio of 1.1766), which should be favourable to the lithium ion storage. Moreover, the Raman scattering peaks detected at 197,486 , and $623 \mathrm{~cm}^{-1}$ correspond to the $F_{2 g}$ modes, and the one at $694 \mathrm{~cm}^{-1}$ can be attributed to the $\mathrm{A}_{1 \mathrm{~g}}$ mode of $\mathrm{Co}_{3} \mathrm{O}_{4} \cdot{ }^{37-39}$

The morphology and structural features of the as-prepared $\mathrm{Co}_{3} \mathrm{O}_{4} / \mathrm{N}$-rGO composite were elucidated via TEM images, which also can confirm the growth of $\mathrm{Co}_{3} \mathrm{O}_{4}$ on the reduced graphene oxide sheets. Fig. 3(b) shows an enlarged image of the indicated section of Fig. 3(a). It can be observed that numerous fine particles with crystallite sizes ranging from 5 to $10 \mathrm{~nm}$ are attached on the reduced graphene oxide sheet. The HRTEM image clearly demonstrates the crystalline spinel structure of the $\mathrm{Co}_{3} \mathrm{O}_{4}$ nanocrystals on the $\mathrm{N}$-doped $\mathrm{rGO}$ sheet. The lattice fringes with spacing of $0.46 \mathrm{~nm}$ and $0.24 \mathrm{~nm}$ in Fig. 3(c) can be attributed to the (111) and (311) planes of cubic $\mathrm{Co}_{3} \mathrm{O}_{4}$, respectively. Comparing the TEM images of the $\mathrm{Co}_{3} \mathrm{O}_{4} / \mathrm{N}-\mathrm{rGO}$ composite with those of the bare $\mathrm{Co}_{3} \mathrm{O}_{4}$ (Fig. S2) and the $\mathrm{Co}_{3} \mathrm{O}_{4} / \mathrm{rGO}$ (Fig. S3), we found that the crystal size and aggregation of $\mathrm{Co}_{3} \mathrm{O}_{4}$ nanocrystals in the composite samples are significantly smaller than in the bare $\mathrm{Co}_{3} \mathrm{O}_{4}$ sample (particle size 20-30 nm), demonstrating that rGO sheets could effectively hinder the growth and aggregation of $\mathrm{Co}_{3} \mathrm{O}_{4}$ crystals during synthesis. Also, the distribution of $\mathrm{Co}_{3} \mathrm{O}_{4}$ particles on the N-rGO is more uniform than on the rGO. It is a strong benefit that the uniform distribution of $\mathrm{Co}_{3} \mathrm{O}_{4}$ nanocrystals on the rGO can restrict the aggregation or restacking of graphene layers during
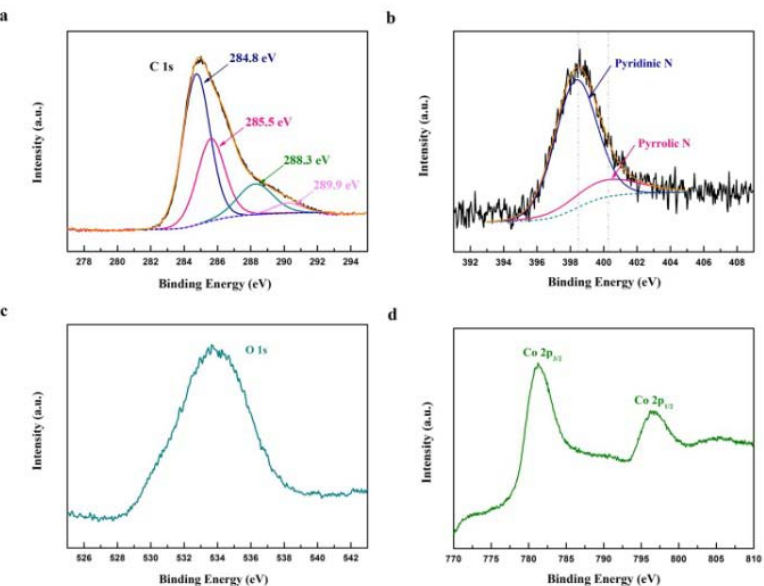

Fig. 4 XPS spectra of all elements of the $\mathrm{Co}_{3} \mathrm{O}_{4} / \mathrm{N}-\mathrm{rGO}$ sample.

the reduction reaction, which effectively reduces the loss of highly active surface area ${ }^{9}$ and preserves the advantages of rGO in charge and discharge. It is expected that the good interlinks between $\mathrm{Co}_{3} \mathrm{O}_{4}$ nanocrystals and $\mathrm{rGO}$ sheets could have benefits for electron transport through the excellent electrical conductor rGO to the nanoparticles and therefore enhance the electrochemical performance.

XPS measurements were carried out to analyze the chemical composition of the obtained surface layer of $\mathrm{Co}_{3} \mathrm{O}_{4} / \mathrm{N}-\mathrm{rGO}$. 
Curve-fitting of the $\mathrm{C}$ 1s spectra was performed to identify the functional group species. The main peak centered at $284.8 \mathrm{eV}$ could be attributed to $\mathrm{sp}^{2}$ hybridized $\mathrm{C}$ atoms in the reduced graphene oxide, and the left part can be resolved into three components centered at 285.5, 288.3, and $289.9 \mathrm{eV}$, which can be assigned to $\mathrm{N}-\mathrm{sp}^{2} \mathrm{C},-\mathrm{C}=\mathrm{O}$, and $\mathrm{COOH}$, respectively. ${ }^{40,}{ }^{41}$ The results proved that the nitrogen atoms were successfully doped onto the reduced graphene oxide. In terms of nitrogen, the $\mathrm{N} 1 \mathrm{~s}$ peak of the $\mathrm{Co}_{3} \mathrm{O}_{4} / \mathrm{N}$-rGO sample has been fitted to pyridinic $\mathrm{N}$ $(398.3 \mathrm{eV})$ and pyrrolic $\mathrm{N}(400.2 \mathrm{eV})$. The electron energy loss spectra (EELS) mapping further confirm the existence of $\mathrm{N}$ element, and the distribution of $\mathrm{N}$ in the graphene is uniform (see Supplementary Information Fig. S4). It was reported that carbon atoms are more chemically active on the edges or defect sites in the graphene plane than within the plane ${ }^{22}$ and that they are inclined to be replaced by pyridinic $\mathrm{N}$ at these chemically active sites. $^{25,42}$ The doped nitrogen atoms provide favorable nucleation and anchoring sites for $\mathrm{Co}_{3} \mathrm{O}_{4}$ nanocrystals because of their coordination with Co cations. ${ }^{31}$ Therefore, there are more $\mathrm{Co}_{3} \mathrm{O}_{4}$ nanocrystals on the edge than the inner area of the N-doped rGO, which can be observed from the TEM images. Fig. 4(c) shows the presence of the $\mathrm{O} 1 \mathrm{~s}$ core level centered at $533.6 \mathrm{eV}$. The two characteristic peaks of Co 2p at 795.8 and 780.9 eV shown in Fig. 4(d) are assigned to the Co $2 \mathrm{p}_{1 / 2}$ and Co $2 \mathrm{p}_{3 / 2}$ spin-orbital splitting photoelectrons of $\mathrm{Co}_{3} \mathrm{O}_{4}$.

A comparison of the charge/discharge cycling performances of the bare $\mathrm{Co}_{3} \mathrm{O}_{4}, \mathrm{Co}_{3} \mathrm{O}_{4} / \mathrm{rGO}$, and $\mathrm{Co}_{3} \mathrm{O}_{4} / \mathrm{N}-\mathrm{rGO}$ is shown in Fig. 5(a). The cells were cycled at a current density of $100 \mathrm{~mA} \mathrm{~g}^{-1}$ for the first five cycles, and then at $400 \mathrm{~mA} \mathrm{~g}^{-1}$ for the remaining cycles. After 50 cycles, the bare $\mathrm{Co}_{3} \mathrm{O}_{4}$ electrode exhibits a poor capacity of $53.2 \mathrm{~mA} \mathrm{~h} \mathrm{~g}^{-1}$, with only $6.5 \%$ retention of the $6^{\text {th }}$ cycle capacity, which can be associated with the severe particle aggregation and pulverization resulting from the inevitable damage to the particles. In contrast, both the $\mathrm{Co}_{3} \mathrm{O}_{4} / \mathrm{rGO}$ and the $\mathrm{Co}_{3} \mathrm{O}_{4} / \mathrm{N}$-rGO composites show good capacity retention upon cycling. The $\mathrm{Co}_{3} \mathrm{O}_{4} / \mathrm{N}-\mathrm{rGO}$ sample delivered a discharge capacity of $882.2 \mathrm{~mA} \mathrm{~h} \mathrm{~g}^{-1}$ at the $6^{\text {th }}$ cycle, which gradually decreases to $766.4 \mathrm{~mA} \mathrm{~h} \mathrm{~g}^{-1}$ at the $50^{\text {th }}$ cycle, with a high retention rate of $86 \%$. Typical charge-discharge curves of the $\mathrm{Co}_{3} \mathrm{O}_{4} / \mathrm{N}-\mathrm{rGO}$ composite electrode for the $1^{\text {st }}, 5^{\text {th }}, 10^{\text {th }}$, and $50^{\text {th }}$ cycles (with the cell cycled at $100 \mathrm{~mA} \mathrm{~g}^{-1}$ for the first 5 cycles and at $400 \mathrm{~mA} \mathrm{~g}^{-1}$ for the rest of the cycles) are shown in Fig. 5(b). The initial discharge and charge capacities are $1413.2 \mathrm{~mA} \mathrm{~h} \mathrm{~g}^{-1}$ and 991.7 $\mathrm{mA} \mathrm{h} \mathrm{g}{ }^{-1}$, respectively, showing an initial coulombic efficiency of $70.1 \%$, which is higher than that of the $\mathrm{Co}_{3} \mathrm{O}_{4} / \mathrm{rGO}$ (68.2\%) (see Supplementary Information Fig. S5). The improved initial coulombic efficiency demonstrates that the nitrogen doping could suppress the decomposition of the electrolyte, the formation of the solid electrolyte interface (SEI) layer by the surface side reaction of graphene with the electrolyte. ${ }^{43}$ In the initial discharge process, there is a stable voltage plateau at about $1.0 \mathrm{~V}$ and then a decrease to the cut-off voltage of $0.01 \mathrm{~V}$, which is associated with the formation of $\mathrm{Li}_{2} \mathrm{O}$ accompanying a complete reduction of cobalt. The as-prepared composite still exhibits a reversible capacity of $775.2 \mathrm{~mA} \cdot \mathrm{h} \mathrm{g}^{-1}$ after 50 discharge/charge cycles at the relatively higher current density of $400 \mathrm{~mA} \mathrm{~g}^{-1}$.

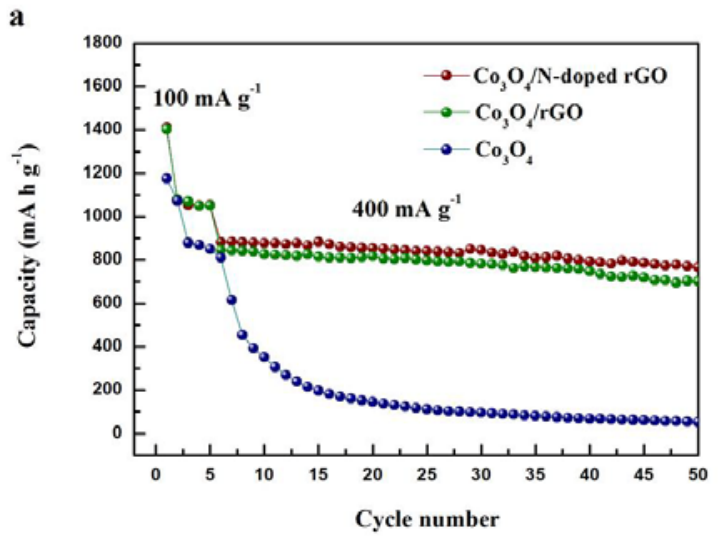

b

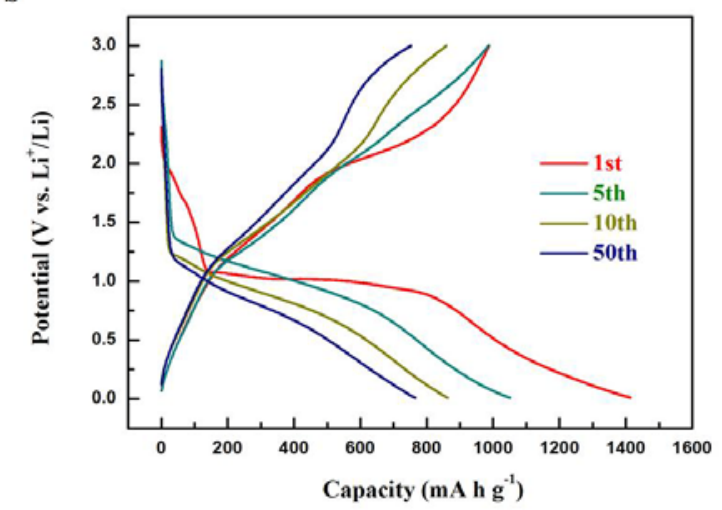

c

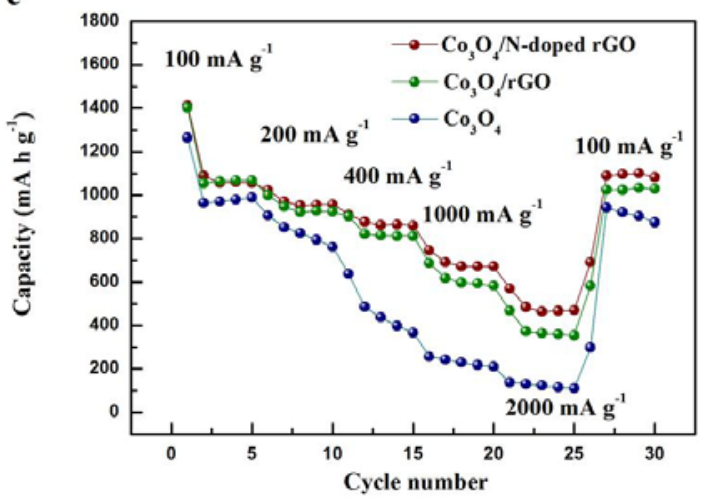

Fig. 5 (a) Comparison of the cycling performance of bare $\mathrm{Co}_{3} \mathrm{O}_{4}$, $\mathrm{Co}_{3} \mathrm{O}_{4} / \mathrm{rGO}$, and $\mathrm{Co}_{3} \mathrm{O}_{4} / \mathrm{N}$-rGO at a current density of $100 \mathrm{~mA} \mathrm{~g}^{-1}$ for the first five cycles and $400 \mathrm{~mA} \mathrm{~g}^{-1}$ for the remaining cycles; (b) galvanostatic charge-discharge profiles of $\mathrm{Co}_{3} \mathrm{O}_{4} / \mathrm{N}-\mathrm{rGO}$ for the $1^{\text {st }}, 5^{\text {th }}, 10^{\text {th }}$, and $50^{\text {th }}$ cycles; (c) Comparison of rate capability of bare $\mathrm{Co}_{3} \mathrm{O}_{4}, \mathrm{Co}_{3} \mathrm{O}_{4} / \mathrm{rGO}$, and $\mathrm{Co}_{3} \mathrm{O}_{4} / \mathrm{N}$-rGO at different current densities.

To comprehensively elucidate the effects of the rGO and nitrogen doping on the electrochemical performance of the obtained samples, the rate capabilities of the bare $\mathrm{Co}_{3} \mathrm{O}_{4}$, $\mathrm{Co}_{3} \mathrm{O}_{4} / \mathrm{rGO}$, and $\mathrm{Co}_{3} \mathrm{O}_{4} / \mathrm{N}$-rGO are presented in Fig. 5(c) at various current densities from $100 \mathrm{~mA} \mathrm{~g}^{-1}$ to $2000 \mathrm{~mA} \mathrm{~g}^{-1}$ and then back to $100 \mathrm{~mA} \mathrm{~g}^{-1}$ again. Except for the initial cycle, stable capacities were obtained for all three samples at a current density of $100 \mathrm{~mA} \mathrm{~g}^{-1}$. In the following cycles, the capacity of the bare $\mathrm{Co}_{3} \mathrm{O}_{4}$ decreased from $800 \mathrm{~mA} \mathrm{~h} \mathrm{~g}^{-1}$ at $200 \mathrm{~mA} \mathrm{~g}^{-1}$ to $110 \mathrm{~mA} \mathrm{~h}$ $\mathrm{g}^{-1}$ at $2000 \mathrm{~mA} \mathrm{~g}^{-1}$ In contrast, both $\mathrm{Co}_{3} \mathrm{O}_{4} / \mathrm{rGO}$ and $\mathrm{Co}_{3} \mathrm{O}_{4} / \mathrm{N}-$ 
rGO exhibit rather better rate capability under the same test conditions, especially the $\mathrm{Co}_{3} \mathrm{O}_{4} / \mathrm{N}-\mathrm{rGO}$ electrode. $\mathrm{Co}_{3} \mathrm{O}_{4} / \mathrm{N}-\mathrm{rGO}$ delivers discharge capacities of 1100, 950, 860, 670, and $460 \mathrm{~mA}$ $\mathrm{h} \mathrm{g}^{-1}$ at different current densities of 100, 200, 400, 1000, and $2000 \mathrm{~mA} \mathrm{~g}^{-1}$, respectively. Such a pronounced improvement in rate capability can be ascribed to the unique network structure of $\mathrm{Co}_{3} \mathrm{O}_{4} / \mathrm{N}-\mathrm{rGO}\left(\mathrm{Co}_{3} \mathrm{O}_{4} / \mathrm{rGO}\right)$ composite, in which $\mathrm{N}-\mathrm{rGO}$ or rGO serves as a mechanical and electronic framework, providing electronic conduction pathways and improving electronic conductivity. Compared with rGO, N-rGO in the composites has better electrical conductivity, and the doped nitrogen atoms provide favorable nucleation and anchoring sites for $\mathrm{Co}_{3} \mathrm{O}_{4}$ nanocrystals, ${ }^{31}$ improving the uniformity of the $\mathrm{Co}_{3} \mathrm{O}_{4}$ distribution, and therefore, further improving the electrochemical performance, especially the rate capability of the composite materials. The results are further confirmed through electrochemical impedance spectroscopy (EIS) (see Supplementary Information Fig. S6). In the high-medium frequency region, it could be observed that the diameter of the characteristic semicircle for the $\mathrm{Co}_{3} \mathrm{O}_{4} / \mathrm{N}-\mathrm{rGO}$ is smaller than that for the $\mathrm{Co}_{3} \mathrm{O}_{4} / \mathrm{rGO}$, indicating that nitrogen doping could lower the contact and charge-transfer resistance of the sample. In addition, the nitrogen doping could introduce a large number of defects on the rGO, which could further enhance its lithium storage properties and electrochemical performance. ${ }^{42}$ It is worth noting that the capacity of $\mathrm{Co}_{3} \mathrm{O}_{4} / \mathrm{N}-\mathrm{rGO}$ is higher than that of $\mathrm{Co}_{3} \mathrm{O}_{4} / \mathrm{rGO}$ on returning to the low current rate of $100 \mathrm{~mA} \mathrm{~g}^{-1}$, indicating better reversibility after nitrogen doping. The electrochemical performance of our $\mathrm{Co}_{3} \mathrm{O}_{4} / \mathrm{N}-\mathrm{rGO}$ is better than that of the cobalt oxide/graphene nanocomposite reported by Wang et al. ${ }^{44}$, the cobalt oxide nanoparticles on graphene nanosheets reported by Hsieh et al., ${ }^{45}$ as well as the grapheneencapsulated mesoporous $\mathrm{Co}_{3} \mathrm{O}_{4}$ composite microspheres reported by Yang et al. ${ }^{46}$ in terms of rate capability, and the cobalt oxide nanowall arrays on reduced graphene oxide sheets reported by Zhu et al. ${ }^{47}$ in terms of cycling performance.

In summary, the excellent electrochemical performance of $\mathrm{Co}_{3} \mathrm{O}_{4} / \mathrm{N}$-rGO can be attributed to: 1 ) the small particle size of $\mathrm{Co}_{3} \mathrm{O}_{4}(5-10 \mathrm{~nm})$, which reduces the path length for lithium ion migration during the charge/discharge process and increases the contact areas between the electrolyte and the active materials, as well as preventing rGO from stacking; 2) the presence of N-rGO, which offers easy pathways for electrons, providing a good conductive matrix for the $\mathrm{Co}_{3} \mathrm{O}_{4}$ nanoparticles; 3 ) the ability of $\mathrm{N}$-rGO to also work as an elastic buffer substrate to accommodate the volume changes of $\mathrm{Co}_{3} \mathrm{O}_{4}$ in the processes of lithium ion insertion/extraction; and 4) better structural stability and electrical conduction due to the good connection of the individual $\mathrm{Co}_{3} \mathrm{O}_{4}$ nanoparticles to the N-rGO. Nitrogen doping introduces defects and pyridinic $\mathrm{N}$ on the $\mathrm{rGO}$, thus leading to the formation of disordered carbon structure, which tends to be electronaccepting and provides anchor sites for the $\mathrm{Co}_{3} \mathrm{O}_{4}$ nanoparticles.

\section{Conclusions}

Nitrogen doped reduced graphene oxide with $\mathrm{Co}_{3} \mathrm{O}_{4}$ nanocrystals attached was successfully fabricated via the hydrothermal technique. The as-obtained $\mathrm{Co}_{3} \mathrm{O}_{4} / \mathrm{N}-\mathrm{rGO}$ revealed a uniform distribution of $\mathrm{Co}_{3} \mathrm{O}_{4}$ nanoparticles between 5-10 nm in size on the nitrogen doped reduced graphene oxide sheets. The lithium storage properties of the composite materials were investigated. It was found that the $\mathrm{Co}_{3} \mathrm{O}_{4} / \mathrm{N}$-rGO electrode exhibits excellent rate capability and cycling stability compared to both bare $\mathrm{Co}_{3} \mathrm{O}_{4}$ and $\mathrm{Co}_{3} \mathrm{O}_{4} / \mathrm{rGO}$ electrodes, which could be attributed to the fact that the $\mathrm{N}$-doped reduced graphene sheet serves as a conductive matrix and an inhibiting agent towards the aggregation and growth of $\mathrm{Co}_{3} \mathrm{O}_{4}$ nanocrystals, as well as a buffering agent for the accommodation of the volume changes during the cycling process. In addition, the nitrogen doping provides defects that can act as lithium storage and anchoring sites for $\mathrm{Co}_{3} \mathrm{O}_{4}$ nanocrystals, which improves the connection of $\mathrm{Co}_{3} \mathrm{O}_{4}$ to the rGO sheets and thus the structural stability of the material.

\section{Acknowledgements}

This work was funded by the Australian Research Council (ARC) through a Discovery project (DP1094261). The authors also would like to thank Dr. Tania Silver at the University of Wollongong for critical reading of the manuscript.

\section{Notes and references}

${ }^{a}$ Institute for Superconducting and Electronic Materials, University of Wollongong, Wollongong, NSW 2522, Australia. Tel: + 6124221522 5; E-mail:zguo@uow.edu.au

${ }^{b}$ School of Mechanical, Materials \& Mechatronics Engineering, University of Wollongong, NSW 2522, Australia

c. Institute of Applied Chemistry, Xinjiang University, Urumqi, Xinjiang 830046, China

† Electronic Supplementary Information (ESI) available. See DOI: 10.1039/b000000x/

1. P. Poizot, S. Laruelle, S. Grugeon, L. Dupont, J. M. Tarascon. Nature, 2000, 407, 496.

2. K. Kang, Y. S. Meng, J. Bréger, C. P. Grey, G. Ceder. Science, 2006, 311, 977.

3. J. M. Tarascon, M. Armand. Nature, 2001, 414, 359.

4. H. Pan, L. Zhao, Y.-S. Hu, H. Li, L. Chen. ChemSusChem, 2012, 5, 526.

5. Y. Li, B. Tan, Y. Wu. Nano Lett., 2007, 8, 265.

6. K. M. Shaju, F. Jiao, A. Debart, P. G. Bruce. Phys. Chem. Chem. Phys., 2007, 9, 1837.

7. J. Wang, G. Du, R. Zeng, B. Niu, Z. Chen, Z. Guo, S. Dou. Electrochim. Acta, 2010, 55, 4805.

8. P. Zhang, Z. P. Guo, Y. Huang, D. Jia, H. K. Liu. J. Power Sources, 2011, 196, 6987.

9. Z.-S. Wu, W. Ren, L. Wen, L. Gao, J. Zhao, Z. Chen, G. Zhou, F. Li, H.-M. Cheng. ACS Nano, 2011, 4, 3187.

10. M. G. Kim, J. Cho. Adv. Funct. Mater., 2009, 19, 1497.

11. Y. Wang, H. J. Zhang, L. Lu, L. P. Stubbs, C. C. Wong, J. Lin. ACS Nano, 2010, 4, 4753.

12. N. Du, H. Zhang, B. D. Chen, J. B. Wu, X. Y. Ma, Z. H. Liu, Y. Q. Zhang, D. R. Yang, X. H. Huang, J. P. Tu. Adv. Mater., 2007, 19, 4505.

13. D. Wang, D. Choi, J. Li, Z. Yang, Z. Nie, R. Kou, D. Hu, C. Wang, L. V. Saraf, J. Zhang, I. A. Aksay, J. Liu. ACS Nano, 2009, 3, 907.

14. S.-M. Paek, E. Yoo, I. Honma. Nano Lett., 2008, 9, 72.

15. E. Yoo, J. Kim, E. Hosono, H.-s. Zhou, T. Kudo, I. Honma. Nano Lett., 2008, 8, 2277.

16. G. Wang, X. Shen, J. Yao, J. Park. Carbon, 2009, 47, 2049. 
17. B. Zhang, Q. B. Zheng, Z. D. Huang, S. W. Oh, J. K. Kim. Carbon, 2011, 49, 4524.

18. Y. Shi, L. Wen, F. Li, H.-M. Cheng. J. Power Sources, 2011, 196, 8610.

19. A. C. Ferrari. Solid State Commun., 2007, 143, 47.

20. A. M. Rao, P. C. Eklund, S. Bandow, A. Thess, R. E. Smalley. Nature, 1997, 388, 257.

21. J. Liang, Y. Jiao, M. Jaroniec, S. Z. Qiao. Angew. Chem. Int. Ed., 2012, 51, 11496.

22. X. Wang, X. Li, L. Zhang, Y. Yoon, P. K. Weber, H. Wang, J. Guo, H. Dai. Science, 2009, 324, 768.

23. Y. Wang, Y. Shao, D. W. Matson, J. Li, Y. Lin. ACS Nano, 2010, 4, 1790.

24. C. Ma, X. Shao, D. Cao. J. Mater. Chem., 2012, 22, 8911.

25. X. Li, H. Wang, J. T. Robinson, H. Sanchez, G. Diankov, H. Dai. J. Am. Chem. Soc., 2009, 131, 15939.

26. X. Li, D. Geng, Y. Zhang, X. Meng, R. Li, X. Sun. Electrochem. Commun., 2011, 13, 822.

27. Z. Ding, L. Zhao, L. Suo, Y. Jiao, S. Meng, Y.-S. Hu, Z. Wang, L. Chen. Phys. Chem. Chem. Phys., 2011, 13, 15127.

28. L. Zhao, Y.-S. Hu, H. Li, Z. Wang, L. Chen. Adv. Mater., 2011, 23, 1385.

29. M. Du, C. Xu, J. Sun, L. Gao. Electrochim. Acta, 2012, 80, 302.

30. H. Mousavi, R. Moradian. Solid State Sciences, 2011, 13, 1459.

31. Y. Liang, Y. Li, H. Wang, J. Zhou, J. Wang, T. Regier, H. Dai. Nat Mater, 2011, 10, 780.

32. W. S. Hummers, R. E. Offeman. J. Am. Chem. Soc., 1958, 80, 1339.

33. D. Li, M. B. Muller, S. Gilje, R. B. Kaner, G. G. Wallace. Nat Nano, 2008, 3, 101.

34. S. Q. Chen, Y. Wang. J. Mater. Chem., 2010, $20,9735$.

35. K. N. Kudin, B. Ozbas, H. C. Schniepp, R. K. Prud'homme, I. A. Aksay, R. Car. Nano Lett., 2007, 8, 36.

36. J. Shen, Y. Hu, M. Shi, X. Lu, C. Qin, C. Li, M. Ye. Chem. Mater., 2009, 21, 3514.

37. H. Kim, D.-H. Seo, S.-W. Kim, J. Kim, K. Kang. Carbon, 2011, 49, 326.

38. B. Li, H. Cao, J. Shao, G. Li, M. Qu, G. Yin. Inorg. Chem., 2011, 50, 1628.

39. J. Jiang, L. Li. Mater. Lett., 2007, 61, 4894.

40. A. L. M. Reddy, A. Srivastava, S. R. Gowda, H. Gullapalli, M. Dubey, P. M. Ajayan. ACS Nano, 2010, 4, 6337.

41. P. Han, Y. Yue, Z. Liu, W. Xu, L. Zhang, H. Xu, S. Dong, G. Cui. Energy Environ.Sci., 2011, 4, 4710.

42. K. Zhang, P. Han, L. Gu, L. Zhang, Z. Liu, Q. Kong, C. Zhang, S. Dong, Z. Zhang, J. Yao, H. Xu, G. Cui, L. Chen. ACS Appl. Mat. Interfaces, 2012, 4, 658.

43. Z.-S. Wu, W. Ren, L. Xu, F. Li, H.-M. Cheng. ACS Nano, 2011, 5, 5463.

44. G. Wang, J. Liu, S. Tang, H. Li, D. Cao. J. Solid State Electrochem., 2011, 15, 2587.

45. C.-T. Hsieh, J.-S. Lin, Y.-F. Chen, H. Teng. J. Phys. Chem. C., 2012, 116, 15251.

46. X. Yang, K. Fan, Y. Zhu, J. Shen, X. Jiang, P. Zhao, C. Li. J. Mater. Chem., 2012, 22, 17278.

47. J. Zhu, Y. K. Sharma, Z. Zeng, X. Zhang, M. Srinivasan, S. Mhaisalkar, H. Zhang, H. H. Hng, Q. Yan. J. Phys. Chem. C, 2011, 115, 8400 . 